\title{
P-67
}

\section{Molecular Relationship and Biosynthetic Potential of Endophytic Bacteria}

\author{
Rahim.R ${ }^{1, *}$, Sultan. $\mathrm{S}^{1}$, Bhore.S.J ${ }^{2}$ and Weber J.F.F ${ }^{1}$ \\ ${ }^{I}$ Atta-ur-Rahman Institute For Natural Product Discovery (RiND), Faculty of Pharmacy, UniversitiTeknologi MARA \\ (UiTM), PuncakAlam Campus, Bandar PuncakAlam, Selangor DarulEhsan, Malaysia; ${ }^{2}$ Faculty of Applied Sciences, \\ AIMST University, Bedong-Semeling Road, 08100 Bedong, Kedah, Malaysia; E-mail: rahimrohani89@gmail.com
}

Endophytic bacteria live inside plant tissues without adverse effect to the host were isolated and identified using 16s rRNA analysis by AIMST University's researchers. From the 998 of isolated strain, Bacillus altiunidis, B.amyloliquefaciens, and B.thuringiensis are choosen for the study. A phylogenetic tree has been build in an attempt to identify possible relationship between these endophytes using the neighbor joining method with 1000 bootstraps. However no cluster form between the bacteria either based on plant host family or geographical region of collection. Growing bacteria is done in 96 deep well microtiter plates which is fast and cost effective. Three types of elicitors $\mathrm{Fe}_{2} \mathrm{SO}_{4}, \mathrm{MgSO}_{4}$, and $\mathrm{Cu}_{2} \mathrm{SO}_{4}$, were added to the growth medium to vary the growth conditions in the hope of producing different secondary metabolite. Solid phase extraction used to extract the secondary metabolites from bacterial cultures. The extraction method was modified from a standard operating procedure that was developed for fungal metabolites. The secondary metabolite profiling was done using ultra high performance liquid chromatography (UHPLC). The metabolites profiles were compared to identify variations in strain's metabolomes. The structures of compound of interest will be elucidate using UV , capillary NMR and LC-MS.

Keywords: Endophytic bacteria, microtiter plate, elicators, phylogenetic tree, secondary metabolite. 